\title{
The Influence of Market Maker System on the New Third Board Market of China
}

\author{
Qianqian Ai \\ International Business School in Shaanxi Normal University \\ Xi'an 710062, P.R. China \\ 1275835898@qq.com
}

\author{
Zhenni Fang \\ The Australian National University \\ Harfor Fund Management Co., Ltd \\ Shanghai 200000, P.R. China
}

\begin{abstract}
As a significant component of the multi-level capital market in China, the New Third Board Market plays an important role in promoting the financing of small and mediumsized enterprises. For the enhancement of the liquidity of the New Third Board Market, the market maker system was formally introduced in 2014. In this paper, the channels of action of the market maker system were analyzed, and the market maker system is believed to be able to effectively improve the market's liquidity by reducing transaction costs, price discovery and competitive market makers. This paper also puts forward that positive measures should be taken from the following three aspects: market makers, investors and regulators.
\end{abstract}

Keywords-Market maker system; Transaction cost; Price discovery; Liquidity

\section{INTRODUCTION}

In January 2006, China was formally setting up the New Third Board market. At the same time, in order to encourage the development of small and medium-sized enterprises, increase its financing and build a multi-level capital market. In June 19, 2013, the executive meeting of the State Council decided to expand the New Third Board pilot to the whole country.

The purpose of the establishment of the New Third Board is to achieve financing for small and medium-sized enterprises. However, because of the single transaction system, the number of listed companies is growing slowly and the volume less. In order to change this situation, in August 25, 2014, the New Third Board market of our country formally introduced the market maker system. Since then, China's trading system has changed from a single agreement pricing to a multitransaction system where the agreement pricing and market maker system are concurrent. The introduction of market maker system attracted a large number of enterprises to list on the New Third Board. By November 2017, there are 11,628 companies were listed, which represented an increase of more than ten times compared with 1,107 in August 2014. In the same period, the total number of listed companies on the Shanghai Stock Exchange and the Shenzhen Stock Exchange was only 3,426 . This shows the rapid development of the New Third Board market.

The market maker system is mainly through promoting the liquidity of the market to realize the financing function of the New Third Board. Liquidity is the most important goal in the stock market, the sufficient liquidity can promote the stock exchange, so that the interests of the investors and the shareholders of the company can be realized, the efficiency of the resources allocation is improved, and the liquidity plays an important role in the exploration of information, reasonable pricing and market stability. But whether the effect of introducing this system is the same as expectation, because of the short time of the New Third Board, the domestic research on the liquidity is still in its infancy. There is no clear conclusion on whether the market maker system can promote the liquidity of the New Third Board, and the problems of the market maker system are lacking of research and discussion. Based on this background, this paper studies the influence of market maker system on the liquidity of the New Third Board, and uses theoretical analysis to explore the role channel of market maker's action on liquidity. Lastly, combine the market maker system of foreign mature capital market, and put forward some policy suggestions for the future direction of China's reform.

\section{LITERATURE REVIEW}

At present, the foreign research on the market maker system is relatively mature. A large number of studies focus on the role of the market maker system in the market quality and market efficiency.

In China we mainly study the role of market makers in the inter-bank bond market. In recent years, with the introduction of the New Third Board's market maker system, scholars have gradually begun to explore the role of market makers in the New Third Board and the improvement of liquidity, but most have focused on theoretical research

\section{A. Theoretical research on foreign market maker system}

Pagano and Roell (1996) ${ }^{[7]}$ pointed out that compared with the bidding system, the risk of market maker system is even lower. The market maker system and the bidding system have their own advantages, but by analyzing the performance of the market, we can explore which system is more appropriate . Chen Yiqin (2000) $)^{[1]}$ analyzed the performance of European and American markets and found that compared with the bidding system, the market maker system can effectively promote the increase in trading volume and the relative stability of prices. In addition, scholars have found that compared with monopolistic market makers, the competitive 
market maker system's profit is decreasing, and the liquidity can be increased by reducing the cost of the transaction.

\section{B. Theoretical research on China market maker system}

Research on the China market maker system mainly focuses on the bond market and is relatively abundant. However, the research on the New Third Board mainly focus on the introduction of the market maker system and the impact on market liquidity.

Chai Zhipeng (2009) ${ }^{[2]}$ used the turnover rate and the bidask spread as indicators to measuring market liquidity. Through empirical tests, the bond market should adopt a market-maker system as the main transaction system. The implementation of the market maker system was aimed at strengthening market liquidity. Tang Yuwei (2013) ${ }^{[3]}$ reached the same conclusion through empirical evidence. The market maker system is conducive to reducing transaction costs among investors, increasing market efficiency and enhancing liquidity. However, Wu Lei et al. (2017) ${ }^{[5]}$ used the bilateral quotation data of market makers in the bond market and the state space model to find that a competitive market maker system does not improve the liquidity of the market, nor does it have price discovery capability. At the same time, she found that the Foreign banks, one of the market makers, have demonstrated stronger price discovery capabilities than domestic large banks. In the future, we can consider appropriately expanding the participation of foreign banks.

Ma Linna et al. (2015) ${ }^{[4]}$ analyzed the current situation of the New Third Board market and found that the overall liquidity of the market improved significantly, but the difference between the listed companies was strong, and the market maker system was more conducive to the discovery of the stock value. Xue Shuang (2017) ${ }^{[6]}$ used market maker data before December 31, 2015, and used dummy variables to perform horizontal and vertical empirical analysis. The results show that the market maker system can promote the flow of the market compared with the transfer of agreements. The higher the number of market makers, the higher the liquidity of their shares.

Most studies have concluded that the market maker system helps to increase the level of market liquidity. However, at present, the implementation of the market maker system in China still encounters a series of problems and needs continuous improvement and supervision.
III. ANALYSIS OF THE ROLE OF THE MARKET MAKER SYSTEM IN THE LIQUIDITY OF THE NEW THIRD BOARD

The implementation of the market maker system is to promote the liquidity of the market. China and foreign scholars have also continuously confirmed that the market maker system can improve the market's liquidity, but it lacks an analysis of its role as a channel of action. In the process of this analysis, we can find possible problems in the implementation of the market maker system, which can help policy makers formulate relevant improvement measures. This paper explains the mechanism of the behavior of market makers on the liquidity of the New Third Board through the following three channels.

\section{A. Market makers increase market liquidity by reducing transaction costs}

Transaction costs play an important intermediary role between the market's trading mechanism and operating efficiency. The lower the transaction cost, the higher the efficiency of the market and the higher the market's liquidity. The transfer of the agreement and market makers generate different costs in the transaction process: First, from the explicit costs, transactions between markets require a certain amount of fees and taxes, but this part of the fee relatively small, the difference between the two trading mechanisms is small. The second is the hidden cost, which is relatively high. The implicit cost includes the bid-ask spread, search cost, delay cost, and market-influenced cost. If the stock transfers by agreement, the trader needs a lot of time if he wants to conduct a transaction. Searching for counterparties has higher search costs. At the same time, since both parties to the transaction are individual traders, the negotiation of the transaction takes a long time. During this period, the price of the stock may change, which will increase the delay cost. The market-making transfer is through the market-maker to act as a trading counterparty, the trader directly enters into a transaction with a market maker who owns a large number of stocks, avoids searching for costs, and does not need to wait. Therefore, the market maker system reduces the transaction costs compared to the agreement transfer, thereby increasing the market's liquidity.

\section{B. Market makers increase market liquidity through price discovery}

Reasonable market pricing can promote the accomplish of effective transactions, reduce traders' waiting time, thereby increasing the market's trading volume and market's liquidity. Compared with the transfer of agreements, the market-based transfer method is more conducive to the discovery of stock value and reasonable market transaction price. We can find in the following aspects: First, the market makers in the New Third Board are brokerage firms. Compared with ordinary investors, they have more specialized investment knowledge and are also more sensitive to changes in policies. At the same time, they are exposed to a large number of companies every day. They know a large number of the company information, so that they can discover the intrinsic value of the company. Second, market makers have their own channels of information, they can get the hidden information than ordinary investors, so their information advantage is more obvious. 
Third, market makers need to conduct a large number of bilateral quotations every day to meet the both parties. Market makers need to consider their own commercial reputation, C. Market makers increase market liquidity through introducing a competitive market-maker system

According to the difference in the number of market makers per stock, the market maker system can be divided into monopolistic market makers and competitive market makers. In monopolistic market makers, there is only one market maker for each stock, but the competitive market maker system can allow multiple quotes from multiple market makers for each stock. Under the competitive market-maker system, multiple market makers quoting the same stock. According to the theory of game theory, the more market makers, the more competitive the market. In order to win more customers, the market makers will reduce their own profits as much as possible, which can attract more customers, can make the bid-ask spread lower and liquidity increase. At the same time, the market makers will deliver a part of the information, and the growing number of market makers will increase the information in the market, thereby reducing information asymmetry and improving the market's liquidity.

\section{SUGGESTIONS ON THE NEW THIRD BOARD TRADING SYSTEM IN CHINA}

\section{A. Improve the incentive mechanism for market makers, and enrich the market makers.}

Market maker as a commercial profit organization, the most important purpose of its participation in the market is to gain income. At present, the profit of the market maker of the New Third Board comes first from the direct investment income, which means to buy the initial stock at a lower price from the shareholders before enterprises are listed in the New Third Board, or to subscribe to the stock of the recommended company through its own subsidiary. The second is to make market income and obtain the buying and selling price through two-way quotations. But at present, the New Third Board market of high quality trading opponents are less and less, and with the competitive market maker system, the sale price difference is becoming smaller and smaller. Because of the lack of competitors, the risk of market makers holding large numbers of stocks is greatly increased. A large number of market makers began to focus on direct investment, and gradually reduced enthusiasm for the market making, so that the market liquidity declined. The mature market abroad gives market makers a series of preferential facilities, policy support, and encourage market makers to take part in market making activities. The market maker of China undertakes the market making risk too much, lacks the impetus to invest and make the market. Therefore, when formulating the relevant policy, we should pay more attention to the incentive construction of the market maker and give its inner motivation to make the market.

In addition, there is only brokerages as market maker in the New Third Board, which results in a single market maker, a single counterparty and not enough transaction depth. By joining a new type of market maker and cultivating a multilevel market maker, it means that there are more trading rivals and trading opportunities to activate the market. The make reasonable price judgments, and find reasonable prices through continuous transactions.

more trading volume a market makes, the greater the value of its stock will come back to its true value.

\section{B. Enrich the types of market makers and cultivate multi-level and high-quality market makers}

At present, the market makers who undertake the market-making business in the New Third Board market are all brokerage firms. This results in a single market maker structure single counterparty, and insufficient transaction depth. Only brokers as market makers have their limitations, and for market makers, they are required to serve as intermediary agencies for the transaction, and require them to have a certain value judgment for the market-making company. By adding new types of market makers and cultivating multi-level market makers, it means that there are more counterparties and trading opportunities, and the market can be activated. The more trading volume of the corresponding market-making stocks, will make the stock returns to its true value. At present, private equity firms are trying to join the market-making team, can increase the market-making institutions of the New Third Board, and can also increase the financing capacity of private equity institutions.

By appropriately adjusting the conditions for market makers to enter, improve the quality of market makers, and cultivate high-quality market makers, at the same time, different market makers matching the size of different companies can be set up to meet the requirements of different companies and can effectively improve the quality of service provided by marketers, it will promote liquidity in the New Third Board market.

\section{Reduce barriers to entry for investors}

In order to avoid financial risk, the investors in the New Third Board market are mainly institutional investors, and the entry threshold for individual investors is relatively high. At present, the threshold of individual investors is set to 5 million yuan, but the individual investors in the market can meet this condition relatively less. Therefore, most of the individual investors who are optimistic about the New Third Board enterprises cannot participate in it, and the liquidity improvement of the New Third Board market is relatively limited. Previously, the high restrictions on the entry threshold for investors are due to the lack of market regulation and the fear of a large number of retail investors to bring financial risks. But now, with the improvement of the construction of the New Third Board market and the expansion of the market tolerance, the qualification of investors can be relaxed. First of all, we can reduce the entry threshold of investors from the whole, encourage all kinds of funds to pour into the New Third Board market and meet the financing needs of the New Third Board enterprises. Secondly, in order to prevent the risk further, the investors of different levels can be invested in different levels of enterprises, so that the investors with smaller capital can also find a match. Investment is made by enterprises. Through a large number of investors to enhance the liquidity of the New Third Board market. 


\section{D. perfect the construction of market supervision system}

The New Third Board market not only needs to improve the liquidity of the market, but also needs to improve the quality of the market makers. In China, the market maker system is constantly advancing and is constantly improving. However, because of the short development time, there are still many problems. Therefore, the regulators and the participants in the market need to continue to work hard and improve. First, from the perspective of regulators, regulators need to strictly enforce the law. The conditions for listing enterprises to be fulfilled must be strictly enforced, information disclosure and listing of enterprises should be further clarified. In addition, it is necessary to supervise the intermediaries such as brokerages to satisfy their qualifications and whether they can seriously implement the entry threshold of investors. Regulators should stop in time for non conforming behavior .Secondly, for market makers, it is necessary to strengthen their own risk management requirements, undertake the two-way offer obligation of listed companies, and timely disclose information. The audit system is set up within the market maker. Internal audit is conducted at any time, and problems in the market making process are found in time for continuous adjustment.

\section{CONCLUSION}

As an important part of China's multi-level capital market, the New Third Board provides an important venue for the financing of small and medium-sized enterprises in China. The introduction of a market-making system further enhances the liquidity of the New Third Board. This paper analyzes the impact of the market maker system on the liquidity of the New Third Board to analyze the impact of the market maker system on liquidity. First, market makers can reduce the invisible transaction costs such as search cost and bid-offer price to improve liquidity. Businesses contribute to the discovery of stock prices, increase liquidity through price discovery. In addition, allow multiple market makers to quote each stock at the same time, improving liquidity through a competitive environment. Finally, suggestions are made from market makers, investors, and regulators.

\section{REFERENCES}

[1] Chen Yi Qin. Look at the establishment of China's market maker system from NASDAQ, [J]. financial research, 2000 (02): 80-84

[2] Chai Zi Peng. Influence of market maker system on interbank bond market liquidity [D]. Fudan University, 2009.

[3] Tang Yu Wei. Influence of market maker system on interbank bond market liquidity in China [D]. Jilin University, 2013.

[4] Ma Lina, Li Zheng, Lin Jianjun. Influence of market maker system on China's new third board market [J]. Research on technology economics and management, 2015 (08): 104-108.

[5] Wu Lei, Su Chang. Interbank bond market maker price discovery capability research [J]. Stock market guide, 2017 (03): 44-55+74.

[6] Xue Shuang, Chen Fengbo. New third board maker system and stock mobility [J]. Accounting friend, 2017 (15): 14-21.

[7] Pagano M, Roell A. Transparency and Liquidity: A Comparison of Auction and Dealer Markets with informed trading, The Journal of Finance, Vol.51, No.2, S. 579-611[J]. Journal of Finance, 1996, 51(2):579-611.

[8] Schultz, P, 2001 "Corporate Bond Trading Costs and Practices: A Peek Behind the Curtain", Journal of Finance, 56: $677 \sim 698$ 